\title{
Impact of melamine and its derivatives on the properties of poly(vinyl acetate)-based composite wood adhesive
}

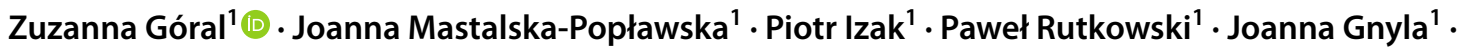 \\ Tomasz M. Majka² $\cdot$ Krzysztof Pielichowski ${ }^{2}$
}

Received: 24 May 2019 / Accepted: 20 October 2020 / Published online: 9 November 2020

(c) The Author(s) 2020

\begin{abstract}
A fire retardant composite adhesive for bonding wood and wood-based elements has been developed and characterized. To obtain the enhanced fire-proof properties of the wood adhesive dispersion based on the poly(vinyl acetate) (PVAc), ceramic fillers (17.5 wt\% total)—alumina, silica, kaolin and glass fibers were applied. Moreover, fire retardants such as melamine, melamine phosphate and melamine polyphosphate (up to $7 \mathrm{wt} \%$ ) were also used. Thermal analysis (TG-DSC), strength tests, rheology, $\mathrm{pH}$ and flammability measurements (PCFC) were performed. The best properties of the adhesive were achieved for ceramic additives supported by melamine phosphate. A slight improvement of shear strength, shift of the last decomposition step of PVAc (residue degradation) towards higher temperatures by about $50{ }^{\circ} \mathrm{C}$, reduction in mass loss from $100 \mathrm{wt} \%$ to less than $70 \mathrm{wt} \%$ and about 30-40\% improvement of flammability parameters such as heat release capacity, total heat release or peak heat release rate were found compared to the pure poly(vinyl acetate) adhesive.
\end{abstract}

\section{Introduction}

Poly(vinyl acetate) (PVAc) water dispersion has been commonly used as a wood adhesive for decades. It is a thermoplastic polymer, relatively cheap and easily applied. Moreover, it does not contain flammable and environmentally harmful solvents such as formaldehyde because its curing process takes place by water evaporation and subsequent creation of hydrogen bonds. However, its adhesive properties deteriorate at higher temperatures (loss of bonding resistance capacity at over $70{ }^{\circ} \mathrm{C}$ ) as well as in fire and humid conditions (Tankut et al. 2016; Chiozza et al. 2018; Kaboorani and Riedl 2011; Toxqui-López et al. 2006; Kim and Kim 2006; Stoeckel et al. 2013).

The research conducted on PVAc adhesives focused on improving thermal or mechanical performance, such as shear strength and thermal stability. It is mainly realized by

Zuzanna Góral

zgoral@agh.edu.pl

1 AGH University of Science and Technology, Faculty of Materials Science and Ceramics, al. Mickiewicza 30, 30-059 Kraków, Poland

2 Cracow University of Technology, Faculty of Chemical Engineering and Technology, ul. Warszawska 24, 31-155 Kraków, Poland copolymerization of vinyl acetate with different monomers or blending it with other adhesives or hardeners (Kaboorani et al. 2012; Chiozzaa and Pizzo 2016; Šedivka et al. 2015). This can also be achieved by the addition of suitable additives, for instance nano-clay (Moya et al. 2015), cellulose nanofibers (Chaabouni and Boufi 2017), nano-TiO and nano- $\mathrm{SiO}_{2}$ (Bardak et al. 2016). However, there is little information on PVAc adhesives made in the fire protection area.

Generally, the reduction in combustibility and production of smoke or toxic fume is realized by using fire retardants and fillers. Fire retardants are compounds that interfere in the combustion process during heating, pyrolysis, ignition or flame spread by action in the vapour or condensed phase through a chemical and/or physical mechanism. Examples of actions are endothermic decomposition, which reduces the temperature of the pyrolysis zone, interruption of exothermic processes by radical mechanism or formation of char that acts as a barrier against the heat. The fillers dilute the polymer and reduce the concentration of decomposition gases. The fire retardancy of polymers is achieved by applying two approaches: additive-physical incorporation of fire retardants into the polymer, and reactive-copolymerization with a fire retardant (Lu and Hamerton 2002; Dasari et al. 2013). For example, nano- $\mathrm{Mg}(\mathrm{OH})_{2}$ was synthesized and mixed 
with poly(vinyl acetate) to improve its thermal stability (Ghanbari et al. 2013); a fire-retarded PVAc composite was prepared by addition of kaolin, talc, $\mathrm{Mg}(\mathrm{OH})_{2}$, zinc borate, glass frit for the sealant application (Al-Hassany et al. 2010); poly(vinyl acetate) was blended with melamine isocyanurate (Rimez et al. 2016) or with ammonium poly(phosphate) (Rimez et al. 2015, 2016).

However, the reduction in the poly(vinyl acetate) flammability is also very important due to its wide range of applications. Improved safety in domestic, public or industrial situations is required by fire-safety standards ( $\mathrm{Lu}$ and Hamerton 2002). Furthermore, wood belongs to rather flammable materials. To ensure the safety of human life in the case of fire, suitable fire protection of wood is necessary (Pajchrowski et al. 2014; Jiang et al. 2014; Arora et al. 2012). A popular way to achieve this is impregnation (Şadiye Yasar et al. 2017; Tsioptsias and Panayiotou 2011; Harada et al. 2009) or application of fireproof coating, mainly intumescent (swelling when exposed to fire or heat) on wood (Li et al. 2017; Harada et al. 2007; Kazmina et al. 2018; Puri and Khanna 2017).

The method proposed here is the application of a fireretardant adhesive. Burning resistance, integrity of bonded materials (integrity of adhesive with material) at high temperatures, minimization of smoke and release of toxic compounds during degradation are examples of the criteria required from these kinds of adhesive. The last two criteria and also the retention of integrity even with only a modest increase in temperature could be the problem (Lees and Moulds 1995).

Along this line of interest, silicon-based fire-retardant adhesive for plywood (Wang et al. 2018) or water glassbased adhesive for particleboard (Lee and Thole 2018) have been developed, but their application to wood is limited. Adhesives based on silicates have a rather basic $\mathrm{pH}$, while wood adhesives should be acidic due to the structure and properties of cellulose (Zenkteler 1996). Other problems of the adhesive application could include low bonding strength, low moisture resistance (Lee and Thole 2018) or environmentally harmful composition, for example by formaldehyde emission (Khatua et al. 2017).

The motivation of the research is to create a fire-retardant adhesive whose joint forms a protective layer during the fire, which significantly limits the spread of fire. It is hoped that the adequate modification of the PVAc adhesive may improve its fire-retardant properties but also ensures fire protection of wood while maintaining its adhesive features.

Hence, the aim of this study was to obtain a PVAcbased adhesive formula with reduced flammability for bonding wood and wood-based elements. The following ceramic materials were selected as fillers:
- kaolin, silica - formation of mineral residue, improve thermal stability and fire retardancy (Lu and Hamerton 2002; Dasari et al. 2013);

- alumina, glass fibers-improve thermal and strength stability (Kaboorani and Riedl 2012; Rasana et al. 2019).

Melamine, melamine phosphate or melamine polyphosphate were added in variable contents up to $7.0 \mathrm{wt} \%$ as the fire retardant. Endothermic processes occur during their decomposition and some part of the heat is absorbed, which results in a temperature decrease. During combustion, melamine polyphosphate may act as a char promoter, which enhances charring of polymer. The formed char could act as a thermal barrier for the heat transfer.

\section{Materials and methods}

\subsection{Materials}

A commercial poly(vinyl acetate) water dispersion (D2) used in this study was purchased from Dragon, Poland. D2 is a water-resistant wood adhesive with durability class D2. The other raw materials (fire retardants and fillers) were as follows: melamine (EasyChem, Poland), melamine phosphate-Ecoret MP (Alwernia, Poland), melamine polyphosphate-Ecoret MPP (Alwernia, Poland), aluminium oxide (Chempur, Poland), kaolin KOC with mineralogical composition of $84.21 \mathrm{wt} \%$ kaolinite, $11.17 \mathrm{wt} \%$ quartz and $4.62 \mathrm{wt} \%$ mica (Surmin-Kaolin, Poland), glass fibre fillerFG 400/030 (Schwarzwälder Textil-Werke, Germany), silica-Arsil (Chemical Plant "Rudniki", Poland).

Oak wood panels (thickness of $8.0 \mathrm{~mm}$, density of $690 \mathrm{~kg} /$ $\mathrm{m}^{3}$ ) and beech wood panels (thickness of $1.4 \mathrm{~mm}$, density of $750 \mathrm{~kg} / \mathrm{m}^{3}$ ) were used for joint and flammability tests, respectively.

\subsection{Preparation of the adhesive mixtures}

Disperlux-Pendraulik laboratory dissolver was used to blend D2 with selected components. Several adhesive mixtures consisting of a constant content of alumina $\left(\mathrm{Al}_{2} \mathrm{O}_{3}\right)$, kaolin (KOC), glass fibers (FG), silica $\left(\mathrm{SiO}_{2}\right)$ and different loadings of melamine compounds (melamine- $\mathrm{M}$, melamine phosphate-MP, melamine polyphosphate-MPP) from 0 to $7 \mathrm{wt} \%$ were prepared. In addition, distilled water was used to improve their rheological properties. The composition of the adhesive mixtures is presented in Table 1 . The samples were mixed at 500 RPM for $30 \mathrm{~min}$, and each component was added into the mixture separately and in the following order: water, $\mathrm{Al}_{2} \mathrm{O}_{3}, \mathrm{FG}, \mathrm{KOC}$, melamine additive, and $\mathrm{SiO}_{2}$ at the end because of its high water absorption. 
Table 1 Composition of the tested adhesive mixtures

\begin{tabular}{|c|c|c|c|c|c|c|c|c|c|}
\hline \multirow[t]{2}{*}{ Sample name } & \multicolumn{9}{|c|}{ Addition [wt \%] } \\
\hline & D2 & M & MP & MPP & Water & FG & $\mathrm{KOC}$ & $\mathrm{Al}_{2} \mathrm{O}_{3}$ & $\mathrm{SiO}_{2}$ \\
\hline M0 & 75.0 & - & - & - & 7.5 & 5.0 & 5.0 & 5.0 & 2.5 \\
\hline M1 & 71.5 & 3.5 & - & - & & & & & \\
\hline M2 & 68.0 & 7.0 & - & - & & & & & \\
\hline M3 & 71.5 & - & 3.5 & - & & & & & \\
\hline M4 & 68.0 & - & 7.0 & - & & & & & \\
\hline M5 & 71.5 & - & - & 3.5 & & & & & \\
\hline
\end{tabular}

\subsection{Viscosity measurement}

The viscosity of the adhesive mixtures was examined using an Anton Paar Physica MCR-301 rheometer in a plate-plate configuration (plate diameter was $25 \mathrm{~mm}$ ). The shear rate was $100 \mathrm{~s}^{-1}$, measuring gap was $0.2 \mathrm{~mm}$, measurement time was $600 \mathrm{~s}$ and temperature was $23^{\circ} \mathrm{C}$.

\section{$2.4 \mathrm{pH}$ measurement}

The $\mathrm{pH}$ of the samples was measured at room temperature using a Jenway $3540 \mathrm{pH}$ meter.

\subsection{Shear strength measurement}

The effect of ceramic and melamine compounds addition on adhesive bond strength of PVAc was examined by means of a longitudinal tensile shear strength test. Two oak panels $(160 \mathrm{~mm} \times 23 \mathrm{~mm} \times 8 \mathrm{~mm})$ were bonded on the tape (bonded surface $23 \mathrm{~mm} \times 23 \mathrm{~mm}$ ) by an adhesive mixture with $945 \mathrm{~g} / \mathrm{m}^{2}$ coverage ( $0.5 \mathrm{~g}$ per sample). The panels were pressed at a pressure of $0.38 \mathrm{~kg} / \mathrm{cm}^{2}$ for $1 \mathrm{~min}$. The samples were dried at room temperature for 1 day, and then at 40 ${ }^{\circ} \mathrm{C}$ for 3 days in a laboratory dryer. After this time, they were conditioned for 7 days in the standard climate until the measurement. The shear test was carried out with a constant crosshead speed of $2 \mathrm{~mm} / \mathrm{min}$ using a Zwick-Roell Z050 testing machine.

Shear strength $\tau$ [MPa] was calculated using the formula: $\tau=F_{\text {max }} / A$, where $F_{\text {max }}[\mathrm{N}]$ is the maximum failure load, and $A\left[\mathrm{~mm}^{2}\right]$ is the bonded test surface $(23 \mathrm{~mm} \times 23 \mathrm{~mm})$. Tests were replicated ten times.

\subsection{Thermal analysis}

Thermal properties of adhesive mixtures were tested using differential scanning calorimetry (DSC) and thermogravimetry (TG). The measurements were taken in air atmosphere using a Netzsch STA 449 F3 thermal analyzer. The samples were heated from 25 to $740{ }^{\circ} \mathrm{C}$ with a heating rate of $10^{\circ} \mathrm{C} /$ min in aluminum oxide crucibles and with an air flow rate of $40 \mathrm{~cm}^{3} / \mathrm{min}$.

\subsection{Pyrolysis combustion flow calorimetry}

The combustibility of adhesive mixtures was evaluated by applying a Pyrolysis Combustion Flow Calorimeter (PCFC) from Fire Testing Technology (FTT). $5 \pm 1 \mathrm{mg}$ of adhesive powder sample was heated under nitrogen flow up to $750{ }^{\circ} \mathrm{C}$ with a heating rate of $1{ }^{\circ} \mathrm{C} / \mathrm{s}$ in the pyrolysis chamber. Then, the volatile thermal degradation products were combined with oxygen and completely oxidized in a combustion furnace at $900{ }^{\circ} \mathrm{C}$. The gas flow was a mixture of $\mathrm{O}_{2} / \mathrm{N}_{2}$ with a flow rate of $20 / 80 \mathrm{~cm}^{3} / \mathrm{min}$.

The material's fire hazard can be determined by the rate at which heat is released during its burning. Heat release capacity (sumHRC) in J/g K was calculated by a ratio of the sum of peak HRR (pHRR - the maximum heat release rate) to the average heating rate in $\mathrm{K} / \mathrm{s}$. The total heat release (THR) in $\mathrm{kJ} / \mathrm{g}$ was equal to the area below the curve of the heat release rate as a function of the pyrolysis temperature. The residue was obtained by weighing a sample before and after the measurement (Lyon and Walters 2004; Schartel et al. 2007).

\subsection{Horizontal burning test}

To verify the effect of the tested adhesive on wood flammability, 5 samples for each composition type were prepared for the horizontal burning test (HB). Two plates of beech wood with dimensions of $130 \mathrm{~mm} \times 13 \mathrm{~mm}$ and a thickness of $1.4 \mathrm{~mm}$ were joined by the glue line $(1.5 \mathrm{~g})$. Then, after drying the samples at room temperature and smoothing their edges, they were stabilized for 7 days at $23{ }^{\circ} \mathrm{C}$ and $50 \%$ relative humidity. The horizontal burning test was carried out according to IEC 60695-11-10 (2014). Each test specimen was marked with two lines perpendicular to the longitudinal axis of the sample $(130 \mathrm{~mm}), 25 \mathrm{~mm}$ and $100 \mathrm{~mm}$ from the end, which was to be exposed to the flame from a burner inclined at an angle of $45^{\circ}$ to the horizontal axis (Fig. 1). The burner was removed from the sample after $30 \mathrm{~s}$ or earlier if the flame front reached the $25 \mathrm{~mm}$ mark. Flame propagation time $t$ in s from the $25 \mathrm{~mm}$ mark to the $100 \mathrm{~mm}$ mark and damaged length $L$ in $\mathrm{mm}$ (between 0 and $75 \mathrm{~mm}$ ) were measured. Linear burning rate $v$ in $\mathrm{mm} / \mathrm{min}$ was calculated, 


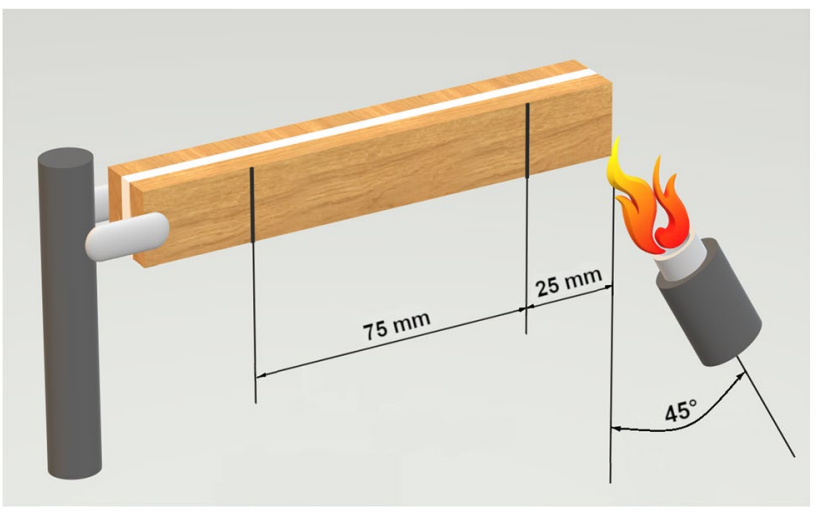

Fig. 1 Scheme of the test stand for the horizontal burning test

using the following equation: $v=60 \mathrm{~L} / \mathrm{t}$. The samples were classified as HB40 or HB75 material in accordance with the criteria given in Table 2.

\section{Results and discussion}

\subsection{Processing part}

The chemical reaction of the wood adhesive should comply with cellulose physico-chemical properties and its $\mathrm{pH}$, safe for wood, should be between 3 and 9. Too high (basic) or too low (acidic) pH could destroy the wood, for example by dissolution or hydrolysation of hemicellulose (Zenkteler 1996). The $\mathrm{pH}$ values of the prepared adhesive samples were between 3.4 and 5.3 (Fig. 2), so they can be successfully applied to wood. The addition of fillers and melamine to D2 adhesive caused a small increase in $\mathrm{pH}$ from 3.63 to 4.29 and to 5.28 respectively. The $\mathrm{pH}$ value of the adhesive mixtures with melamine phosphate (samples M3 and M4) was the closest to D2-below 4.

An important parameter in the adhesion bonding process also is the viscosity of the adhesive. The adhesive needs to form a molecular-level contact with the surface of wood. It should be therefore a liquid in the initial stage of bonding, which can ensure the development of close contact with the substrates. The wetting and flow over a surface of the adhesive, and in some cases also its penetration into the substrate, are required to create the bond. This can be achieved by the appropriate rheological properties of the adhesive, including its viscosity (Rowell 2012). The initial viscosity of pure D2 adhesive was about $4.85 \mathrm{~Pa}$ s. Then, this viscosity increased over time up to $8.89 \mathrm{~Pa}$ s. It means that the bonding process of the adhesive started. The liquid adhesive slowly converted to solid by loss (evaporation) of solvent (water). The addition of ceramic materials (kaolin, alumina, silica and glass fibers) to the poly(vinyl acetate) did not affect the initial and final viscosity value of the mixture, which was also ensured by the application of water. The viscosity of sample M0 was between 4.80 and $8.86 \mathrm{~Pa}$ s. The initial viscosity of sample M3 was also similar to D2 and M0, and was $4.88 \mathrm{~Pa}$ s. Further addition of melamine phosphate up to $7.0 \mathrm{wt} \%$ (M4) or interchangeably melamine (3.5 wt \%-M1, $7.0 \mathrm{wt} \%-\mathrm{M} 2)$ caused its slight increase above $5 \mathrm{~Pa} \mathrm{~s}$, which was related to the higher content of additives. The deterioration of sample M5 (Fig. 3) was probably the effect of too high water absorption by MPP. The $3.5 \mathrm{wt} \%$ content of melamine polyphosphate in the mixture caused a too extreme increase in viscosity, which excluded its use in this composition. The influence of melamine polyphosphate on the adhesive $\mathrm{pH}$ was negligible, so it was not correlated with the viscosity changes.

Generally, final viscosities of all prepared adhesive mixtures, except M3, were comparable to D2 and oscillated around $9 \mathrm{~Pa}$ s. However, the main difference between them was the change in viscosity over time. In comparison to D2, a faster increase in viscosity over time was observed for the other adhesive mixtures (Fig. 4). It could mean a shorter bonding time of these adhesives through faster water evaporation, which directly affects the shorter open time (Zenkteler 1996; Rowell 2012). The reason for this was the presence of additives which can also absorb water from poly(vinyl acetate) dispersion.

The information about bond strength provides the next important parameter of adhesives-shear strength. The values of bond strength measured on shear samples made of oak are given in Fig. 5. The shear strength decreased by about $0.75 \mathrm{MPa}$ after the addition of ceramic additives and water and, then it started to increase with increasing content of melamine phosphate, from $7.97 \pm 0.16 \mathrm{MPa}$ for $3.5 \mathrm{wt} \%$ of MP to $8.87 \pm 0.58 \mathrm{MPa}$ for $7.0 \mathrm{wt} \%$ of MP. An increase in shear strength for the $3.5 \mathrm{wt} \%$ melamine addition and its evident decrease for $7.0 \mathrm{wt} \% \mathrm{con}-$ tent were noted, compared to sample M0. The adhesive mixture with the highest melamine addition has also the lowest bond strength, whereas the one with the maximum load of melamine phosphate has the bond strength with the highest value. The decrease from $8.56 \pm 0.25 \mathrm{MPa}$

Table 2 HB classification for a sample thickness of $3.0 \mathrm{~mm}$

\begin{tabular}{|c|c|c|}
\hline Classification & HB40 & HB75 \\
\hline \multirow{3}{*}{$\begin{array}{l}\text { A material shall } \\
\text { conform to one } \\
\text { of the following } \\
\text { criteria }\end{array}$} & \multicolumn{2}{|c|}{$\begin{array}{l}\text { It does not burn with a flame after the ignition } \\
\text { source is removed }\end{array}$} \\
\hline & \multicolumn{2}{|c|}{$\begin{array}{l}\text { If the test specimens continue to burn with a } \\
\text { flame after removal of the ignition source, the } \\
\text { flame front does not pass the } 100 \mathrm{~mm} \text { mark }\end{array}$} \\
\hline & $\begin{array}{l}\text { If the test flame front } \\
\text { passes the } 100 \mathrm{~mm} \\
\text { mark and it does not } \\
\text { have a linear burn- } \\
\text { ing rate exceeding } \\
40 \mathrm{~mm} / \mathrm{min}\end{array}$ & $\begin{array}{l}\text { If the test flame front } \\
\text { passes the } 100 \mathrm{~mm} \\
\text { mark and it does not } \\
\text { have a linear burning } \\
\text { rate exceeding } 75 \mathrm{~mm} / \\
\text { min }\end{array}$ \\
\hline
\end{tabular}




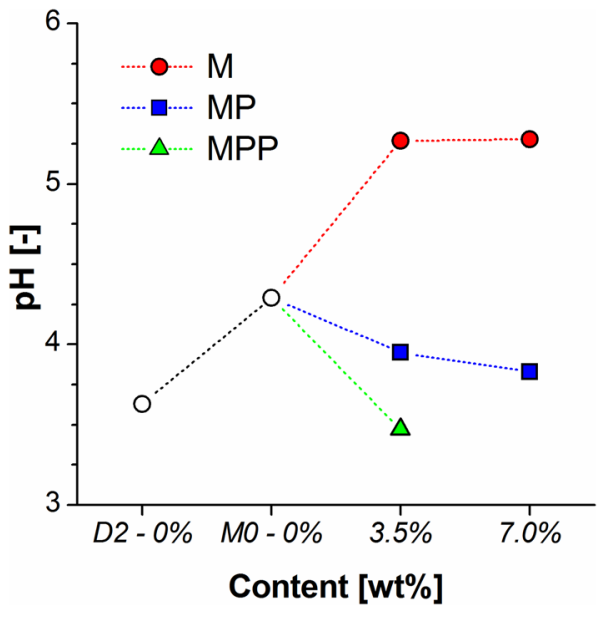

Fig. $2 \mathrm{pH}$ of the tested adhesive mixtures as a function of additives content
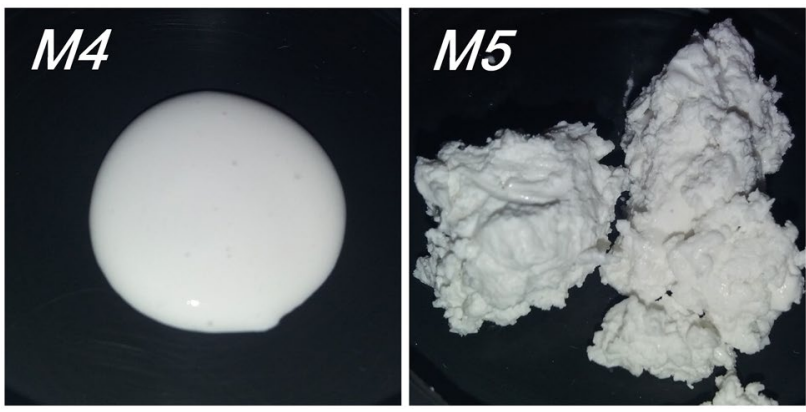

Fig. 3 Comparison of the influence of different melamine additives on the rheology of the prepared adhesive mixture based on the M4 (7 wt\% of MP) and M5 (3.5 wt\% of MPP) samples

to $6.95 \pm 0.62 \mathrm{MPa}$ and increase to $8.87 \pm 0.58 \mathrm{MPa}$ was recorded for sample $\mathrm{M} 2$ and $\mathrm{M} 4$, respectively, compared to the $\mathrm{D} 2$ base.

These various values of shear strength may be related to the viscosity changes over time. The initial viscosity of samples with melamine addition was higher compared to melamine phosphate and for adhesive M2 was the highest (about 5.90 Pa s). It could cause worse wetting of wood surfaces and combined with a shorter open time resulted in weaker wood-adhesive bonding. Sample M1, which had lower viscosity than $\mathrm{M} 2$ in the whole time range, has also a higher shear strength, about 1.23 MPa. However, adhesive mixture M4 had similar viscosity values over time up to $200 \mathrm{~s}$ to M1, but its strength was higher, about $0.69 \mathrm{MPa}$. This can be related to the $\mathrm{pH}$ of the adhesive itself, as well as the used wood type. The $\mathrm{pH}$ of M4 was 3.83 and was lower than M1 (5.27). Oak wood has pH below 4, which makes this adhesive-wood bond more chemically compatible (Zenkteler 1996; Cagle 1973; Bastani et al. 2016).

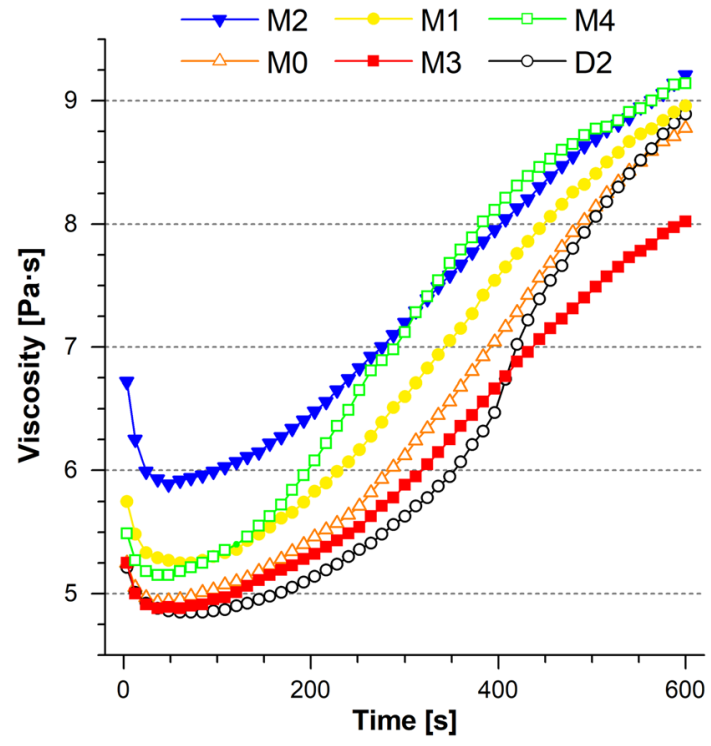

Fig. 4 Viscosity measurement of the tested adhesive mixtures over time

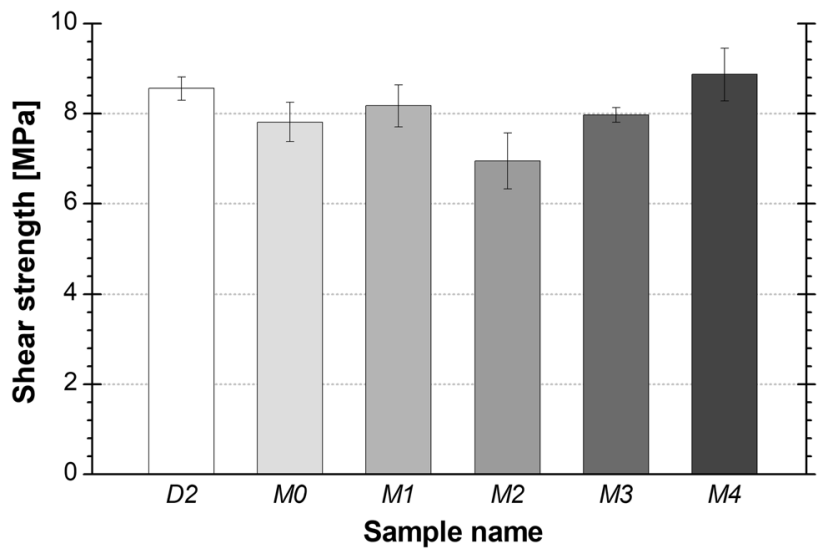

Fig. 5 Shear strength of the prepared adhesive joints measured by a longitudinal tensile shear strength test

\subsection{The fire retardancy part}

\subsubsection{Thermal analysis}

TG-DSC curves of D2 and its prepared modifications are shown in Figs. 6 and 7. Figure 8 presents the 1st derivative of TG curves (DTG). Table 3 presents the mass loss of samples in different temperature ranges compared to PVAc.

Three main degradation steps of PVAc were observed. The first one at $300-400{ }^{\circ} \mathrm{C}$, second at $400-480{ }^{\circ} \mathrm{C}$ and the last one at $480-555^{\circ} \mathrm{C}$. Pure poly (vinyl acetate) is thermally stable up to about $190{ }^{\circ} \mathrm{C}$ (Grassie 1952), which confirms the obtained result. The mass loss of $\mathrm{D} 2$ up to $200{ }^{\circ} \mathrm{C}$ was $5 \mathrm{wt} \%$ and then another $5 \mathrm{wt} \%$ up to $300{ }^{\circ} \mathrm{C}$. The result 
was generally similar to the other adhesive mixtures in this temperature range.

The largest mass loss of D2 (about $64 \mathrm{wt} \%$ ) occurs at a temperature of $300-400{ }^{\circ} \mathrm{C}$, which is related to the small endothermic and slightly larger exothermic peak on the DSC curve at 314 and $349{ }^{\circ} \mathrm{C}$, respectively. This stage of PVAc thermal degradation is associated with the elimination of acetic acid (gas) from the polymer backbone and production of a highly regular unsaturated backbone or polyene (solid) (Al-Hassany et al. 2010; Rimez et al. 2015). The addition of ceramic fillers to poly(vinyl acetate) dispersion caused a decrease in its mass loss to $41 \mathrm{wt} \%$ mainly due to the PVAc content reduction. Aluminum oxide, silica, kaolin and glass fibers are nonflammable fillers and their presence can reinforce the residue (Dasari et al. 2013; Feng et al. 2014).

Melamine phosphate did not affect significantly the mass loss up to $400{ }^{\circ} \mathrm{C}$, while melamine caused slightly faster degradation of adhesive compared to sample M0. Due to evaporation and condensation of melamine in the temperature range $250-380{ }^{\circ} \mathrm{C}$, the formation of melam, melem and melon with the elimination of ammonia and carbon dioxide occurs (Isbasar and Hacaloglu 2012; Wang et al. 2009). This is manifested in the form of an endothermic effect that is observed at $303{ }^{\circ} \mathrm{C}$ on the DSC curve for samples M2-7 wt\% of the melamine addition. However, the onset of MP decomposition occurs in a similar temperature range to poly(vinyl acetate) through two dehydration processes at about $250{ }^{\circ} \mathrm{C}$, leading to the formation of melamine pyrophosphate (MDP) and then melamine polyphosphate (MPP). The first process occurs through a very small endothermic effect around $230{ }^{\circ} \mathrm{C}$ for samples M3 and M4, the second one is overlapped with the degradation processes of PVAc. Above $340{ }^{\circ} \mathrm{C}, \mathrm{NH}_{3}$ is eliminated from melamine phosphates, which is accompanied by heat absorption. An endothermic effect is observed at $401{ }^{\circ} \mathrm{C}$ for M4. As a result, melam pyrophosphate or melam polyphosphate is formed (Wang et al. 2009; Balabanovich 2005).

The next exothermic peaks associated with reorganization of polyene into an aromatic solid residue or char (the 2nd degradation step of PVAc) and with the final degradation of char into $\mathrm{CO}_{2}$ (the 3rd degradation step of PVAc) are observed at $427{ }^{\circ} \mathrm{C}$ and $520{ }^{\circ} \mathrm{C}$ on the DSC curve of D2 (Rimez et al. 2015), which was accompanied by a mass loss by about 14 and 12 wt $\%$, respectively. Dehydroxylation of kaolinite, the main component of kaolin, occurs at $400-700{ }^{\circ} \mathrm{C}\left(\mathrm{Al}_{2} \mathrm{O}_{3} \cdot 2 \mathrm{SiO}_{2} \cdot 2 \mathrm{H}_{2} \mathrm{O} \rightarrow \mathrm{Al}_{2} \mathrm{O}_{3} \cdot 2 \mathrm{SiO}_{2}\right.$

Table 3 Mass loss and temperatures of the thermal effects calculated on the basis of the TG/DSC curves

\begin{tabular}{|c|c|c|c|c|c|c|c|c|c|}
\hline \multirow[t]{2}{*}{ Sample } & \multicolumn{8}{|c|}{ Mass loss [wt $\%$ ] } & \multirow{2}{*}{$\begin{array}{l}\text { Total mass } \\
\text { loss [wt } \%]\end{array}$} \\
\hline & $0-300{ }^{\circ} \mathrm{C}$ & $300-400{ }^{\circ} \mathrm{C}$ & $\mathrm{T}_{\mathrm{p}}\left[{ }^{\circ} \mathrm{C}\right]$ & $400-480{ }^{\circ} \mathrm{C}$ & $\mathrm{T}_{\mathrm{p}}\left[{ }^{\circ} \mathrm{C}\right]$ & $480-555^{\circ} \mathrm{C}$ & $555-740{ }^{\circ} \mathrm{C}$ & $\mathrm{T}_{\mathrm{p}}\left[{ }^{\circ} \mathrm{C}\right]$ & \\
\hline D2 & 10.06 & 63.61 & 314 endo 349 exo & 14.48 & 427 exo & 11.85 & - & 520 exo & 100.00 \\
\hline M0 & 9.39 & 41.11 & 332 exo & 7.87 & - & 10.83 & 0.76 & 502 exo & 69.96 \\
\hline M1 & 12.82 & 39.80 & 335 exo & 6.19 & - & 10.47 & 2.08 & 521 exo & 71.36 \\
\hline M2 & 12.72 & 41.06 & 303 endo 333 exo & 5.57 & - & 9.60 & 3.01 & 529 exo & 71.96 \\
\hline M3 & 10.07 & 40.91 & $\begin{array}{l}225 \text { endo } \\
333 \text { exo }\end{array}$ & 4.98 & - & 5.21 & 7.43 & 555 exo & 68.60 \\
\hline M4 & 9.92 & 40.54 & $\begin{array}{l}229 \text { endo } \\
330 \text { exo }\end{array}$ & 5.95 & 401 endo & 3.21 & 9.85 & 574 exo & 69.47 \\
\hline
\end{tabular}

Fig. 6 TG/DSC profiles and the effect of a melamine and b melamine phosphate on the thermal degradation process of adhesive (a)

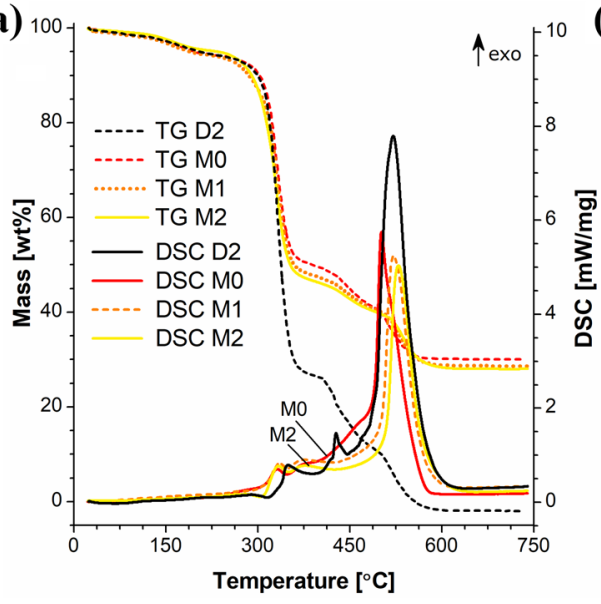

(b)

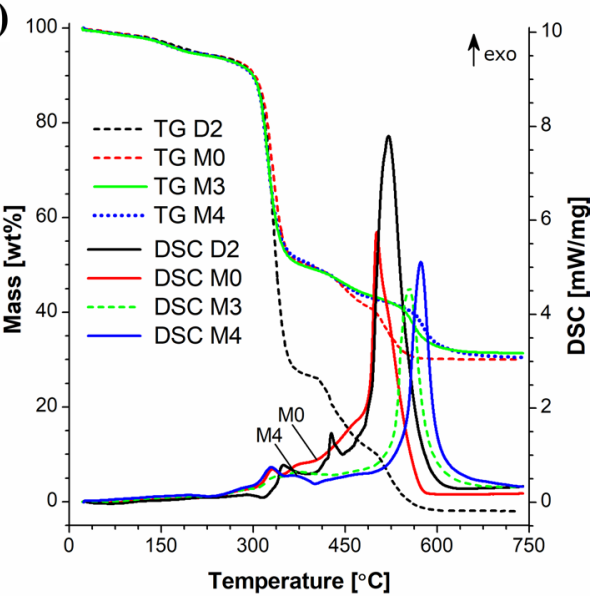


Fig. 7 Zoom on the thermal effects in the temperature range of $200-450{ }^{\circ} \mathrm{C}$ from DSC measurement and the influence of $\mathbf{a}$ melamine and $\mathbf{b}$ melamine phosphate on the thermal degradation process at this stage
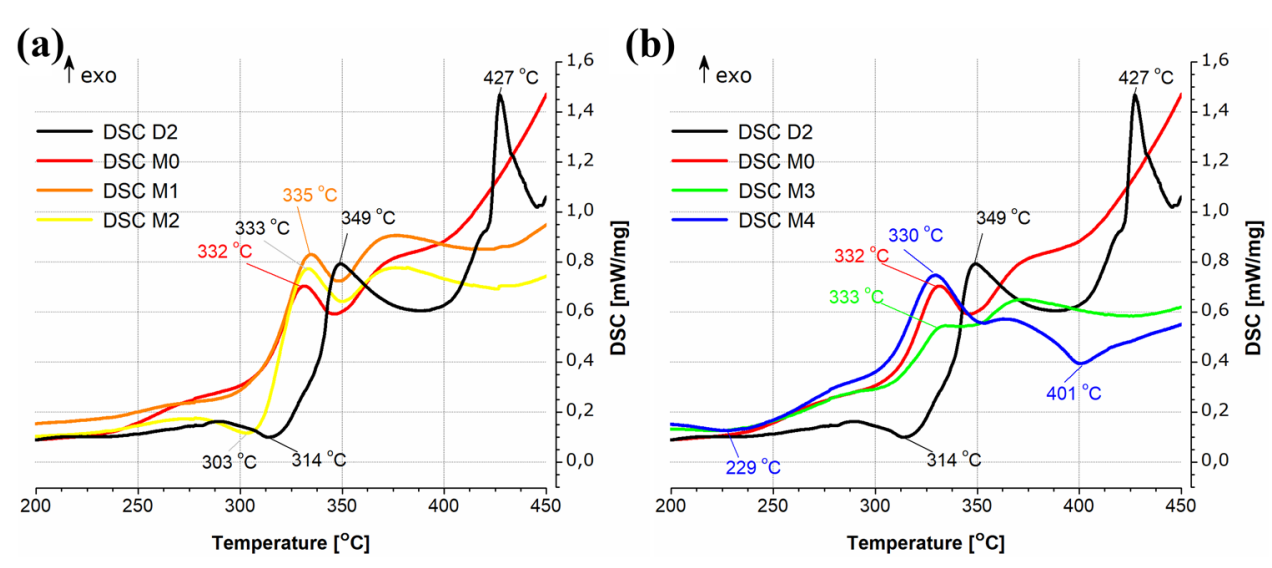

(a)

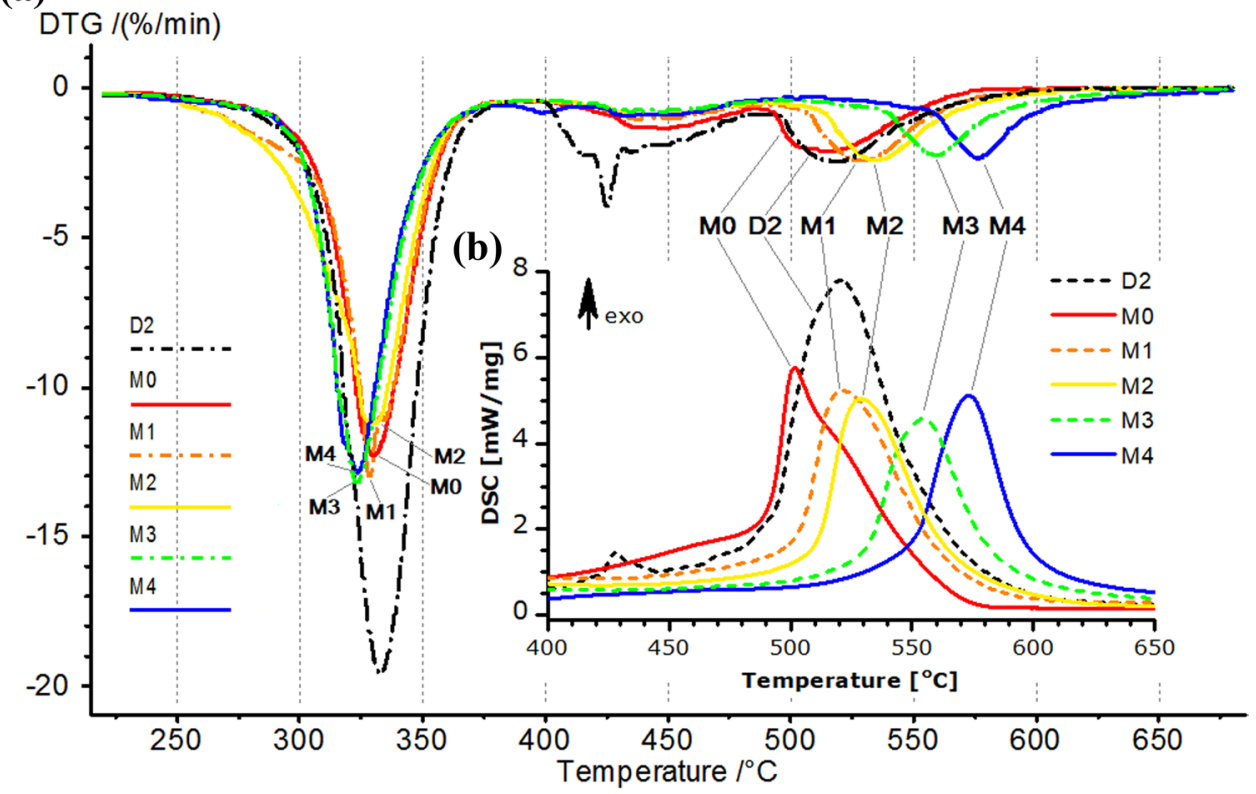

Fig. 8 Thermal analysis result—a DTG, b DSC 
The heat release rate profiles of all samples, except M1 and M2, demonstrated three HRR peaks, which could be related to the individual degradation steps of pure poly(vinyl acetate). The first (the smallest) one at $110-280{ }^{\circ} \mathrm{C}$ connected with the initial decomposition processes of PVAc occurred at low temperatures. The second (maximum) one at $280-400{ }^{\circ} \mathrm{C}$ was related to the elimination of acetic acid from the polymer backbone and production of a highly regular unsaturated backbone or polyene. The last (medium) one at $400-550{ }^{\circ} \mathrm{C}$ was connected with the reorganization of polyene into an aromatic solid residue. A peak at the highest temperatures in DSC (between 500 and $600{ }^{\circ} \mathrm{C}$ ) is not observed in PCFC due to the atmosphere in which the process occurs-char decomposed under air (DSC-TG) but not under nitrogen in PCFC.

The obtained results demonstrated that the maximum heat release $\left(\mathrm{pHRR}_{2}=260 \mathrm{~W} / \mathrm{g}\right)$ at $352{ }^{\circ} \mathrm{C}$ is mainly associated with the combustion of deacetylation products-an autocatalytic reaction (Rimez et al. 2017). The heat release was equal to $11.8 \mathrm{~kJ} / \mathrm{g}$ for these processes; this is more than half of the THR during the entire measurement. The further combustion caused a release of $9.5 \mathrm{~kJ} / \mathrm{g}$ of heat (smaller half of THR) despite the third peak having a smaller maximum value $-\mathrm{pHHR}_{3}=110 \mathrm{~W} / \mathrm{g}$. In total, THR amounted to $22.6 \mathrm{~kJ} / \mathrm{g}$. When compared with other results for PVAc (Schartel et al. 2007), this value is higher by about $3.4 \mathrm{~kJ} / \mathrm{g}$, most likely because D2 is a commercial adhesive and can contain some additives.

In the case of melamine addition, a partial overlapping of 2 peaks in the temperature range of $250-400{ }^{\circ} \mathrm{C}$ was found. This can be related to the earlier release of pyrolysis products of M than in the case of MP. However, the shift of maximum HRR $\left(\mathrm{pHHR}_{2}\right.$ ) to lower temperatures by about $10{ }^{\circ} \mathrm{C}$ was observed for melamine phosphate samples. Pyrolysis of $\mathrm{M}$ and MP occurred earlier than for D2 but the effect of their action was visible at higher temperatures through reduction of heat released above $400{ }^{\circ} \mathrm{C}$ compared to sample M0.

Generally, additives, which were applied, have a beneficial effect on the flammability of D2 adhesive. The addition of kaolin, alumina, silica and glass fibers initiated significant improvement of some flammability parameters. About 30\% decrease in pHRR, sumHRC and THR values and increase in residue from $0 \%$ to above $30 \%$, were obtained (Fig. 10). Then, an additional incorporation of a fire retardant (M or MP) caused a further reduction in some values but to a small extent (less than $10 \%$ ). The effect of melamine phosphate addition on flammability was slightly better than melamine due to lower THR and sumHRC. Moreover, an increase in the M and MP content from 3.5 to $7.0 \mathrm{wt} \%$ was not beneficial. Other parameters, such as THR, increased.

Certainly, the final residue is mineral from mineral additives with a small amount of char. The residue was slightly higher (maximum about $4 \mathrm{wt} \%$ ) compared to thermal analysis results, due to the absence of char decomposition. The decrease in THR, sumHRC and the increase in residue were more or less equal to the filler content (i.e. 17.5-24.5 wt \%). However, some important effects as dilution of gases by the release of inert gases and barrier effect from char cannot be measured in PCFC, which limits the performances resulting from this method.

\subsection{Horizontal burning test}

The linear burning rate values of the samples $v$ are presented in Fig. 11. This parameter decreased as the content of melamine and melamine phosphate in the adhesive increased, but melamine phosphate was more effective. The reduction in the flammability of wood was also visible through the course of the test itself. The flame front reached the $25 \mathrm{~mm}$ mark within $30 \mathrm{~s}$ (around $20 \mathrm{~s}$ ) for all samples, which were joined by the pure D2 adhesive. Wood burned intensely and quickly, the flame was big and turbulent, and the charred parts of the sample were dropping from it. A large release of black smoke was also observed. The addition of ceramic fillers contributed to the reduction in the burning intensity and slower flame propagation, but the $25 \mathrm{~mm}$ mark was also reached within $30 \mathrm{~s}$. The presence of melamine resulted in slower ignition of the sample, and more than two times longer time was needed to reach the $25 \mathrm{~mm}$ mark (sample M2). The wood burned slower and the flame was less intense. The sample, which was joined by the adhesive with the melamine phosphate in its composition, burned the slowest. The flame was small and stable. It moved over

Table 4 Results of the PCFC measurements

\begin{tabular}{lcllllllll}
\hline Sample & $\mathrm{pHRR}_{1}[\mathrm{~W} / \mathrm{g}]$ & $\mathrm{T}_{\mathrm{p} 1}\left[{ }^{\circ} \mathrm{C}\right]$ & $\mathrm{pHRR}_{2}[\mathrm{~W} / \mathrm{g}]$ & $\mathrm{T}_{\mathrm{p} 2}\left[{ }^{\circ} \mathrm{C}\right]$ & $\mathrm{pHRR}_{3}[\mathrm{~W} / \mathrm{g}]$ & $\mathrm{T}_{\mathrm{p} 3}\left[{ }^{\circ} \mathrm{C}\right]$ & $\begin{array}{l}\text { sumHRC } \\
{[\mathrm{J} / \mathrm{g} \mathrm{K}]}\end{array}$ & $\mathrm{THR}[\mathrm{kJ} / \mathrm{g}]$ & $\mathrm{Residue}[\mathrm{wt} \%]$ \\
\hline D2 & 11 & 182 & 260 & 352 & 110 & 471 & 422 & 22.6 & 0.0 \\
M0 & 10 & 190 & 160 & 350 & 84 & 466 & 280 & 15.5 & 32.2 \\
M1 & 8 & 182 & 30,156 & 310,350 & 74 & 464 & 290 & 14.5 & 32.8 \\
M2 & 9 & 172 & 65,145 & 323,351 & 68 & 465 & 314 & 14.9 & 27.1 \\
M3 & 7 & 174 & 185 & 337 & 61 & 461 & 279 & 14.0 & 35.7 \\
M4 & 8 & 173 & 179 & 339 & 63 & 462 & 273 & 14.2 & 32.8 \\
\hline
\end{tabular}


Fig. 9 PCFC measurement results, heat release rate curves versus a pyrolysis temperature (impact of melamine addition), b pyrolysis temperature (impact of melamine phosphate addition), c time (all samples)
Fig. 10 Relative drop in the total heat release (THR), heat release capacity (HRC), maximum peak of heat release rate (PHRR) and mass loss versus pure PVAc (D2)—\%THR, \%HRC, \%PHRR
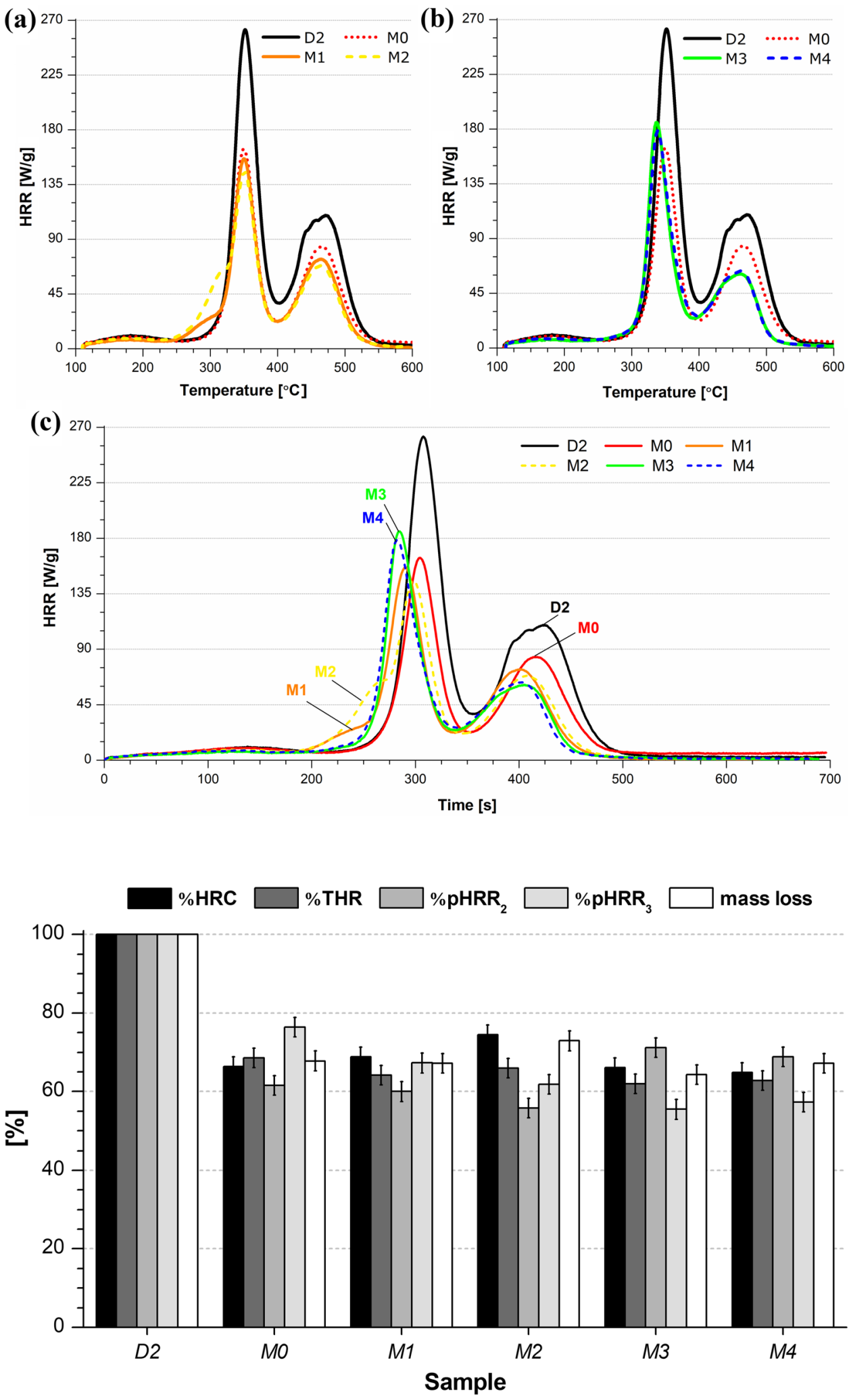

the specimen, but the sample was compact and its charred fragments did not drop from it. The highest integration of samples (the wood plates remained glued) during the measurement was observed for sample M4. Extinguishing of the flame before the $100 \mathrm{~mm}$ mark occurred for 2 out of 5 measurements and the damaged lengths were $66 \mathrm{~mm}$ and $62 \mathrm{~mm}$ respectively. Furthermore, the addition of M and MP caused a reduction in the visible black smoke release. 


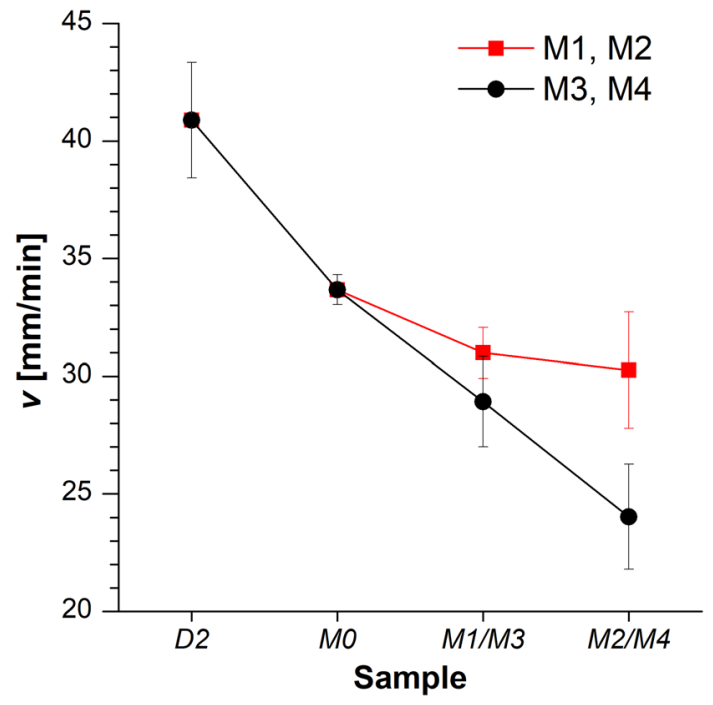

Fig. 11 Horizontal burning test results-linear burning rate $(v)$ of wood samples joined by the prepared adhesive mixtures

Tested wood composites were classified as HB75 (D2) and HB40 (M0-M4) materials for a sample thickness of $3.0 \mathrm{~mm}$.

\section{Conclusions}

Tests on the formulation of a fireproof adhesive for bonding wood and wood-based elements were presented. The impact of ceramic fillers, melamine and its derivatives to D2 commercial wood adhesive based on the poly(vinyl acetate) water dispersion was investigated. Ceramic compounds such as alumina, silica, kaolin and glass fibers were added as nonflammable fillers. One of the melamine's compounds (melamine, melamine phosphate or melamine polyphosphate) was added to the PVAc dispersion as the fire retardant. The impact of melamine, melamine phosphate and melamine polyphosphate was compared.

The ceramic fillers addition (17.5 wt $\%$ total) has a positive effect on thermal stability and fire properties of D2 adhesive. Mass loss, heat release capacity and total heat release were reduced by about more than $30 \%$. Kaolin, glass fibers, alumina and silica fulfilled their function as fire retardants.

The additional incorporation of melamine compounds into the adhesive composition caused a further improvement of some parameters. Generally, they influenced THR, HRC, pHRR and linear burning rate. They did not affect the total mass loss but caused a delay in the PVAc degradation. The shift of their third (and last) decomposition step towards higher temperatures was identified. The results indicate a better effect of melamine phosphate on the prepared adhesive mixture than pure melamine because of lower viscosity, total heat release, heat release capacity and linear burning rate, and higher strength and temperature of degradation. However, melamine caused a higher reduction in the maximum heat release rate $\left(\mathrm{pHRR}_{2}\right)$, but one additional peak overlapped this phenomenon. Moreover, melamine polyphosphate could not be used in this composition because of its too high water absorption. Viscosity and consistency of sample M5 were not adequate for the adhesive.

Thanks to the used additives, an improvement of the strength, thermal and fireproof properties of some adhesive mixtures was obtained compared to the pure poly(vinyl acetate) dispersion. Taking all tests into account, the best parameters were obtained for the sample with $7.0 \mathrm{wt} \%$ of MP addition-M4. In comparison to D2, a slight improvement in the shear strength of about $0.3 \mathrm{MPa}$, a temperature shift of the final degradation of PVAc of about $54{ }^{\circ} \mathrm{C}$, and a reduction in total mass loss of about $30.5 \mathrm{wt} \%$, of THR of about $8.4 \mathrm{~kJ} / \mathrm{g}$ (37\%), of sumHRC of about $149 \mathrm{~J} / \mathrm{g}$ $\mathrm{K}(35 \%)$ and of linear burning rate of about $17 \mathrm{~mm} / \mathrm{min}$ (41\%) were obtained. However, the increased MP content from 3.5 (M3) to $7.0 \mathrm{wt} \%$ (M4) only slightly improved the flammability parameters.

The research demonstrated that M3 and M4 adhesives can have a potential application as fire retardant adhesives designed for bonding wood and wood-based elements.

Acknowledgements This research did not receive any specific grant from funding agencies in the public, commercial, or not-for-profit sectors.

\section{Compliance with ethical standards}

Conflict of interest On behalf of all authors, the corresponding author states that there is no conflict of interest.

Open Access This article is licensed under a Creative Commons Attribution 4.0 International License, which permits use, sharing, adaptation, distribution and reproduction in any medium or format, as long as you give appropriate credit to the original author(s) and the source, provide a link to the Creative Commons licence, and indicate if changes were made. The images or other third party material in this article are included in the article's Creative Commons licence, unless indicated otherwise in a credit line to the material. If material is not included in the article's Creative Commons licence and your intended use is not permitted by statutory regulation or exceeds the permitted use, you will need to obtain permission directly from the copyright holder. To view a copy of this licence, visit http://creativecommons.org/licenses/by/4.0/.

\section{References}

Al-Hassany Z, Genovese A, Shanks RA (2010) Fire-retardant and fire-barrier poly(vinyl acetate) composites for sealant application. Express Polym Lett 4(2):79-93 
Arora S, Kumar M, Kumar M (2012) Catalytic effect of bases in impregnation of guanidine nitrate on Poplar (Populus) wood. J Therm Anal Calorim 107:1277-1286

Balabanovich AI (2005) Thermal decomposition study of intumescent additives: pentaerythritol phosphate and its blend with melamine phosphate. Thermochim Acta 435:188-196

Bardak T, Naci Tankut A, Tankut N, Sozen E, Aydemir D (2016) The effect of nano- $\mathrm{TiO}_{2}$ and $\mathrm{SiO}_{2}$ on bonding strength and structural properties of poly(vinyl acetate) composites. Measurement 93:80-85

Bastani A, Adamopoulos S, Koddenberg T, Militz H (2016) Study of adhesive bondlines in modified wood with fluorescence microscopy and X-ray micro-computed tomography. Int J Adhes Adhes $68: 351-358$

Cagle CV (ed) (1973) Handbook of adhesive bonding. McGraw-Hill, New York

Chaabouni O, Boufi S (2017) Cellulose nanofibrils/polyvinyl acetate nanocomposite adhesives with improved mechanical properties. Carbohyd Polym 156:64-70

Chiozzaa F, Pizzo B (2016) Innovation in poly(vinyl acetate) water resistant D3 glues used in wood industry. Int J Adhes Adhes 70:102-109

Chiozza F, Santoni I, Pizzo B (2018) Discoloration of poly(vinyl acetate) (PVAc) gluelines in wood assemblies. Polym Degrad Stab 157:90-99

Dasari A, Yu Z-Z, Cai G-P, Mai Y-W (2013) Recent developments in the fire retardancy of polymeric materials. Prog Polym Sci 38:1357-1387

Feng Y, Wang B, Wang F, Zhao Y, Liu C, Chen J, Shen C (2014) Thermal degradation mechanism and kinetics of polycarbonate/silica nanocomposites. Polym Degrad Stab 107:129-138

Gasparini E, Tarantino SC, Ghigna P, Pia Riccardi M, CedilloGonzález EI, Siligardi C, Zema M (2013) Thermal dehydroxylation of kaolinite under isothermal conditions. Appl Clay Sci 80-81:417-425

Ghanbari D, Salavati-Niasari M, Sabet M (2013) Preparation of flowerlike magnesium hydroxide nanostructure and its influence on the thermal stability of poly vinyl acetate and poly vinyl alcohol. Compos B 45:550-555

Grassie N (1952) The thermal degradation of polyvinyl acetate, I. Products and reaction mechanism at low temperatures. Trans Faraday Soc 48:379-387

Harada T, Nakashima Y, Anazawa Y (2007) The effect of ceramic coating of fire-retardant wood on combustibility and weatherability. J Wood Sci 53:249-254

Harada T, Matsunaga H, Kataoka Y, Kiguchi M, Matsumura J (2009) Weatherability and combustibility of fire-retardant-impregnated wood after accelerated weathering tests. J Wood Sci 55:359-366

IEC 60695-11-10:2013/AC1:2014 (2014) Fire hazard testing-Part 11-10: Test flames-50 W horizontal and vertical flame test methods. IEC standards

Isbasar C, Hacaloglu J (2012) Investigation of thermal degradation characteristics of polyamide- 6 containing melamine or melamine cyanurate via direct pyrolysis mass spectrometry. J Anal Appl Pyrolysis 98:221-230

Jiang T, Feng X, Wang Q, Xiao Z, Wang F, Xie Y (2014) Fire performance of oak wood modified with $N$-methylol resin and methylolated guanylurea phosphate/boric acid-based fire retardant. Constr Build Mater 72:1-6

Kaboorani A, Riedl B (2011) Improving performance of polyvinyl acetate (PVA) as a binder for wood by combination with melamine based adhesives. Int J Adhes Adhes 31:605-611

Kaboorani A, Riedl B (2012) Nano-aluminum oxide as a reinforcing material for thermoplastic adhesives. J Ind Eng Chem 18:1076-1081
Kaboorani A, Riedl B, Blanchet P, Fellin M, Hosseinaei O, Wang $S$ (2012) Nanocrystalline cellulose (NCC): a renewable nanomaterial for polyvinyl acetate (PVA) adhesive. Eur Polym J 48:1829-1837

Kazmina O, Lebedeva E, Mitina N, Kuzmenko A (2018) Fire-proof silicate coatings with magnesium-containing fire retardant. J Coat Technol Res 15(3):543-554

Khatua PK, Dubey RK, Roymahapatra G, Mishra A, Shahoo SC, Kalawate A (2017) Development of self fire retardant melamineanimal glue formaldehyde (MGF) resin for the manufacture of BWR Ply Board. J Inst Eng India Ser D 98(2):195-202

Kim S, Kim H-J (2006) Thermal stability and viscoelastic properties of MF/PVAc hybrid resins on the adhesion for engineered flooring in under heating system; ONDOL. Thermochim Acta 444:134-140

Lee SJ, Thole V (2018) Investigation of modified water glass as adhesive for wood and particleboard: mechanical, thermal and flame retardant properties. Eur J Wood Prod 76:1427-1434

Lees WA, Moulds RJ (1995) Adhesives and sealants-their use in the fabrication of fire-resisting components and structures. Int J Adhes Adhes 15:95-100

Li X, Zhao Z, Wang Y, Yan H, Zhang X, Xu B (2017) Highly efficient flame retardant, flexible, and strong adhesive intumescent coating on polypropylene using hyperbranched polyamide. Chem Eng J 324:237-250

Lu S-Y, Hamerton I (2002) Recent developments in the chemistry of halogen-free flame retardant polymers. Prog Polym Sci 27:1661-1712

Lyon RE, Walters RN (2004) Pyrolysis combustion flow calorimetry. J Anal Appl Pyrolysis 71:27-46

Moya R, Rodríguez-Zúñiga A, Vega-Baudrit J, Álvarez V (2015) Effects of adding nano-clay (montmorillonite) on performance of polyvinyl acetate (PVAc) and urea-formaldehyde (UF) adhesives in Carapa guianensis, a tropical species. Int J Adhes Adhes 59:62-70

Pajchrowski G, Noskowiak A, Lewandowska A, Strykowski W (2014) Wood as a building material in the light of environmental assessment of full life cycle of four buildings. Constr Build Mater $52: 428-436$

Ptáček P, Opravil T, Šoukal F, Wasserbauer J, Másilko J, Baráček J (2013) The influence of structure order on the kinetics of dehydroxylation of kaolinite. J Eur Ceram Soc 33:2793-2799

Puri RG, Khanna AS (2017) Intumescent coatings: a review on recent progress. J Coat Technol Res 14(1):1-20

Rasana N, Jayanarayanan K, Deeraj BDS, Joseph K (2019) The thermal degradation and dynamic mechanical properties modeling of MWCNT/glass fiber multiscale filler reinforced polypropylene composites. Compos Sci Technol 169:249-259

Rimez B, Rahier H, Biesemans M, Bourbigot S, Van Mele B (2015) Flame retardancy and degradation mechanism of poly(vinyl acetate) in combination with intumescent flame retardants: I. Ammonium poly(phosphate). Polym Degrad Stab 121:321-330

Rimez B, Van Assche G, Bourbigot S, Rahier H (2016) Modelled decomposition kinetics of flame retarded poly(vinyl acetate). Polym Degrad Stab 130:245-256

Rimez B, RahierH, Biesemans M, Bourbigot S, Van Mele B (2017) Modelled decomposition mechanism of flame retarded poly(vinyl acetate) by melamine isocyanurate. $\mathrm{J}$ Therm Anal Calorim 127:2315-2324

Rowell RM (ed) (2012) Handbook of wood chemistry and wood composites. CRC Press, Boca Raton

Şadiye Yasar Ş, Said Fidan M, Yaşar M, Atar M, Alkan E (2017) Combustion properties of impregnated spruce (Picea orientalis L.) wood. Constr Build Mater 143:574-579

Schartel B, Pawlowski KH, Lyon RE (2007) Pyrolysis combustion flow calorimeter: a tool to assess flame retarded PC/ABS materials? Thermochim Acta 462:1-14 
Šedivka P, Bomba J, Böhm M, Boška P (2015) Influence of temperature on the strength of bonded joints. BioResources 10(3):3999-4010

Stoeckel F, Konnerth J, Gindl-Altmutter W (2013) Mechanical properties of adhesives for bonding wood: a review. Int J Adhes Adhes 45:32-41

Tankut N, Bardak T, Sozen E, Naci Tankut A (2016) The effect of different nanoparticles and open time on bonding strength of poly(vinyl acetate) adhesive. Measurement 81:80-84

Toxqui-López S, Olivares-Pérez A, Fuentes-Tapia I (2006) Polyvinyl acetate with cellulose dinitrate holograms. Opt Mater 28:342-349

Tsioptsias C, Panayiotou C (2011) Thermal stability and hydrophobicity enhancement of wood through impregnation with aqueous solutions and supercritical carbon dioxide. J Mater Sci 46:5406-5411
Wang Z, Lv P, Hu Y, Hu K (2009) Thermal degradation study of intumescent flame retardants by TG and FTIR: melamine phosphate and its mixture with pentaerythritol. J Anal Appl Pyrolysis $86: 207-214$

Wang W, Zammarano M, Shields JR, Knowlton ED, Kim I, Gales JA, Hoehler MS, Li J (2018) A novel application of siliconebased flame-retardant adhesive in plywood. Constr Build Mater 189:448-459

Zenkteler M (1996) Adhesives and bonding of wood. Agricultural University of Poznan Publishing House, Poznan

Publisher's Note Springer Nature remains neutral with regard to jurisdictional claims in published maps and institutional affiliations. 